\title{
Pedagogical Aspects Concerning the Student Assessment Process
}

Dana Jucan 


\title{
Pedagogical Aspects Concerning the Student Assessment Process
}

\author{
Dana Jucan ${ }^{a^{*}}$ \\ ${ }^{a}$ Faculty of Psychology and Educational Sciences, Babeş-Bolyai University, 7 Sindicatelor Street, 400015, Cluj-Napoca, Romania \\ *Corresponding author: dana.jucan@ubbcluj.ro
}

\section{Abstract}

Keywords: assessment, assessment methods, assessment strategies, oral assessment, written assessment
In the present study, we aim to identify the methods of assessment employed in universities in order to evaluate the academic performance of students and the efficiency of said methods. To this end, we have applied a semi-structured interview to the third-year students of the Faculty of Psychology and Sciences of Education, specializing in Preschool and Primary Education - a total of 72 subjects. The interview included ten questions concerning the methods of assessment used by teachers during the examination period. To illustrate our point, we will be presenting and analyzing the answers obtained in five of the questions asked. The analysis of the answers given by the students show that the most common method of assessment is the written one, i.e. through exams in the examination period. Students consider this assessment method to be objective because it measures the level of knowledge and skills acquired, but they also consider that the oral assessment method would be more effective because it would measure the level of academic performance in a more precise manner. As such, the present study proposes concrete ways to streamline the assessment process of student learning.
Zusammenfasung

\section{Schlüsselworte:}

Bewertung,

Bewertungsmethoden, Bewertungsstrategien, mündliche Bewertung, schriftliche Bewertung, Lebensqualität
In der vorliegenden Studie wollen wir die Bewertungsmethoden an Universitäten ermitteln, um die akademische Leistung der Studierenden und die Effizienz dieser Methoden zu bewerten. Zu diesem Zweck haben wir ein Semi-strukturiertes Interview mit den Studenten des dritten Jahres der Fakultät für Psychologie und Erziehungswissenschaften mit den Schwerpunkten Vorschule und Grundschulbildung durchgeführt - insgesamt 72 Fächer. Das Interview enthielt zehn Fragen zu den von den Lehrern während des Prüfungszeitraums verwendeten Bewertungsmethoden. Um unseren Standpunkt zu veranschaulichen, werden wir die Antworten, die wir in fünf der gestellten Fragen erhalten haben, präsentieren und analysieren. Die Analyse der von den Schülern gegebenen Antworten zeigt, dass die am häufigsten verwendete Beurteilungsmethode die schriftliche ist, d. H. Durch Prüfungen im Prüfungszeitraum. Die Studierenden betrachten diese Bewertungsmethode als objektiv, da sie das Niveau der erworbenen Kenntnisse und Fähigkeiten misst, sie sind jedoch auch der Ansicht, dass die mündliche Bewertungsmethode wirksamer ist, da sie das Niveau der akademischen Leistung genauer messen würde. Daher schlägt die vorliegende Studie konkrete Wege vor, um den Bewertungsprozess für das Lernen von Schülern zu rationalisieren.

\section{Introduction}

The assessment process consists of checking, measuring, marking, and justifying the academic results of the students by contrasting them with the initial objectives, in order to take decisions for the improvement of the activity in the following stages (Bocoş \& Jucan, 2017). Evaluation represents the knowledge of the effects of the didactic activity, of the students' performance, respectively of the ratio between their performance in a determined timeframe and in a determined pedagogical context and the performances projected by the didactic framework. The main goal of the didactical evaluation is to sustain and support the learning activity of students, the progress of their learning and their knowledge (Stan, 2001). As a complex didactic activity, organically integrated in the teaching process, the assessment aims at identifying the effects of the actions undertaken by the teacher together with the students, so that, based on the information obtained, these actions may be improved over time (Bocoş \& Jucan, 2017). Thus, the teacher's purpose is to obtain and capitalize on information about a number of aspects, in the context of capitalizing on certain didactic activity resources, mainly concerning: obtaining knowledge about student performance, the qualitative and quantitative description of their intellectual, practical and behavioral skills and abilities (Jucan, 2009), making value judgements about them, respectively regarding the concordance between the achieved performance and the one anticipated when the operational objectives were designed, obtaining information about the performance of the teaching staff, about its competencies, obtaining information about the educational curriculum, about its quality, relevance and effectiveness, capitalizing on all the information obtained 
in order to formulate some appreciations and value judgments, making decisions concerning future educational approaches.

\section{Problem statement}

At the moment of assessment, the teacher is permanently referring to the evaluation standards, which express in a concise and clear form the level at which the cognitive and behavioral abilities of the students must be in order to achieve precisely determined educational goals and objectives (Chiș, 2005). In other words, the evaluation standards have normative significance and represent standards in relation to which the teachers can accurately determine the level of training achieved by the students, being able to formulate value judgments and objective comparisons related to their school performance based on them. Aiming at establishing the relationship between the results obtained in the educational process and those expected when designing the operational objectives, the evaluation strategies represent the component of the educational action that validates, namely confirms or denies the attainment of the performances pursued in the instructive-educative activity (Ionescu, 2005). Evaluation methods are means, tools, ways of acting, through which the evaluator obtains information about student performance, their knowledge, their skills, etc., in relation to the objectives proposed and the scientific content studied (Manolescu, 2006). The traditional evaluation methods used in higher education are oral, written, and practical assessment. Using oral assessment, the degree of acquiring knowledge, its correctness, the skill level, the ability to interpret and process the data, the operability of the acquisitions, the applicability of the learned content - these are all verified (Păun \& Potolea, 2002). Written assessment is done with the help of written evaluation papers, which ask the students to express and put down their ideas in writing and to deal with written tasks. The evaluation through tests is a form of modern written assessment, due to the speed of implementation and accuracy / precision in measurement. The test is a written evaluation tool with specific structure, qualities and attributes, among which we mention: it is a complex tool which, through the items it contains, can cover a large area of content and consequently can check the achievement of a large number of objectives of the teaching activity; it offers the possibility of a more accurate, more objective measurement of the performances of the students compared to other evaluation methods, hence the large spread of the tests in the assessment practice; it operates with clear and operational scales for the processing and interpretation of answers. Practical assessment involves the use of practical tasks and occupies a significant place in verifying students' abilities, skills and habits, formed during practical activities.

\section{Purpose of the study}

In the present study, we aim to identify the methods of assessment employed in universities in order to evaluate the academic performance of students and the efficiency of said methods.

\section{Methodology}

To this end, we have applied a semi-structured interview to the third-year students of the Faculty of Psychology and Sciences of Education, specializing in Preschool and Primary Education - a total of 72 subjects. The interview included ten questions concerning the methods of assessment used by teachers during the examination period. To illustrate our point, we will be presenting and analyzing the answers obtained in five of the questions asked.

\section{Findings}

The first question referred to the evaluation method used most often in the examination period by the teachers. The answer options offered to the students were: oral assessment, written evaluation, practical assessment.

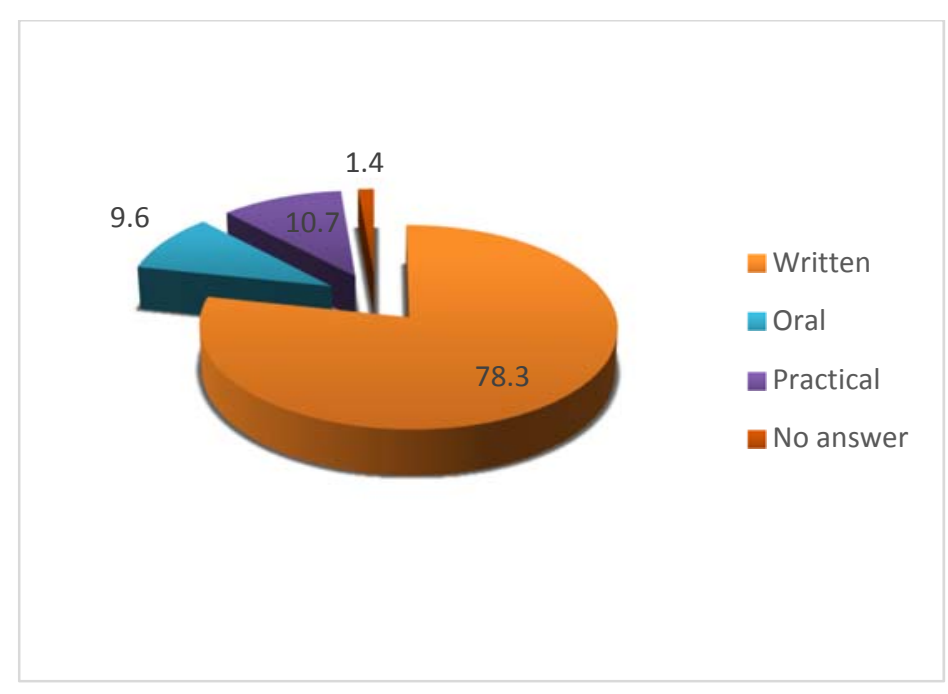

Figure no. 1. The students' replies concerning the methods of assessment in university 
Table no. 1. The students' replies concerning the methods of assessment in university

\begin{tabular}{|l|c|}
\hline $\begin{array}{c}\text { Generally, at university, what method of } \\
\text { assessment is used? }\end{array}$ & $\begin{array}{c}\text { Answers } \\
(\%)\end{array}$ \\
\hline Written & 78,3 \\
\hline Practical & 10.7 \\
\hline Oral & 9.6 \\
\hline No answer & 1,4 \\
\hline
\end{tabular}

Analyzing the students' responses to this question, we found that the most commonly used assessment method by teachers is the written assessment method, with $78.3 \%$ of the answers pointing to this, the practical assessment method is used in $10.7 \%$ of cases, and the oral method in $9.6 \%$ of cases. We consider that the written evaluation method is preferred by the teachers, perhaps because of the large number of students in a department or faculty. In this case, written exams require less time for grading than an oral examination would require.

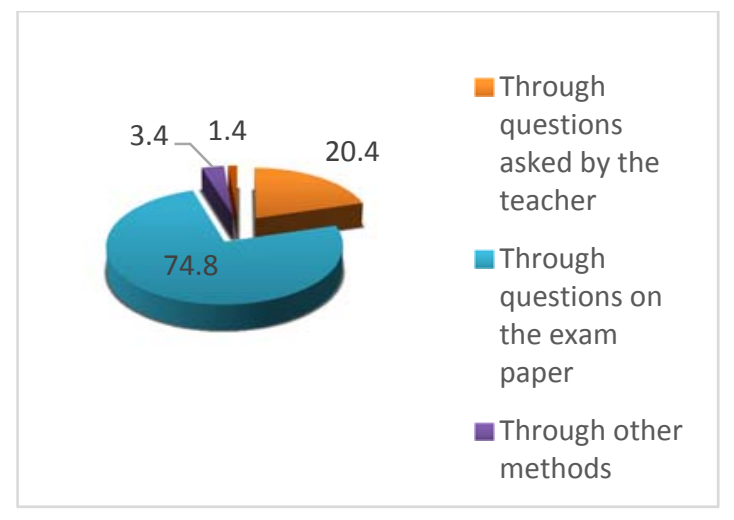

Figure no. 2: The students' replies concerning oral assessment methods

Table no. 2. The students' replies concerning oral assessment methods

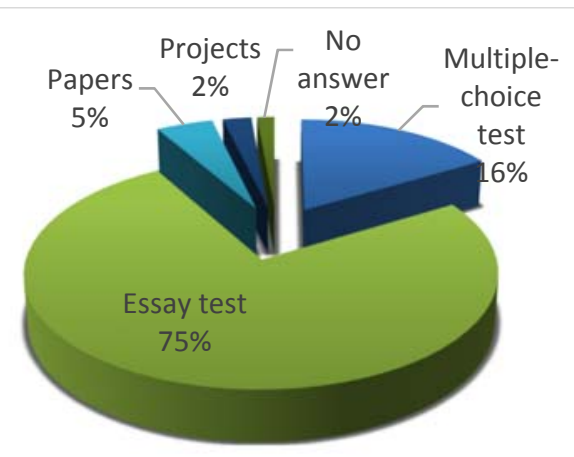

Table no. 3. The students' replies concerning written assessment methods

What are the written assessment methods Answers through which you are most commonly evaluated?

\begin{tabular}{|l|l}
\hline Essay test & 75,3 \\
\hline Multiple-choice test & 16,4 \\
\hline Papers & 4,6 \\
\hline Projects & 2,3 \\
\hline No answer & 1,4 \\
\hline
\end{tabular}

The written assessment methods through which the students are most often evaluated are the written tasks during the examination period - essay tests $(75.3 \%$ of the answers), multiple choice tests (16.4\% of the answers), papers ( $4.6 \%$ of responses), projects (2.3\% of responses).

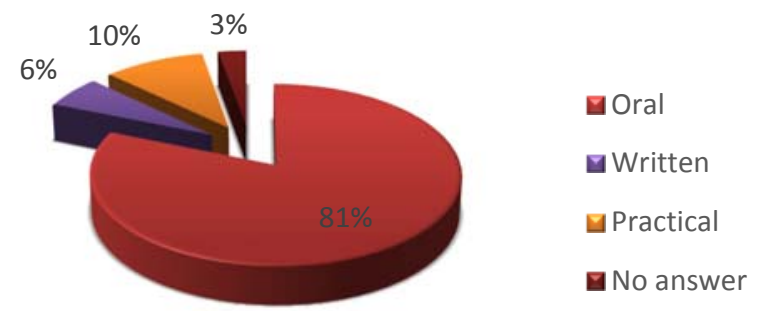

Figure no. 4. The students' replies concerning the efficiency of assessment methods

Table no. 4. The students' replies concerning the efficiency of assessment methods

\begin{tabular}{|l|l}
$\begin{array}{l}\text { Which method of assessment do you } \\
\text { consider to be the most objective? }\end{array}$ & $\begin{array}{c}\text { Answers } \\
(\%)\end{array}$ \\
\hline Oral & 81,2 \\
\hline Practical & 10,1 \\
\hline Written & 5,9 \\
\hline No answer & 2,8 \\
\hline
\end{tabular}

Students consider oral assessment as the most objective $(81.2 \%)$, and practical and written assessments are considered less objective ( $10.1 \%$ and $5.9 \%$ respectively). 


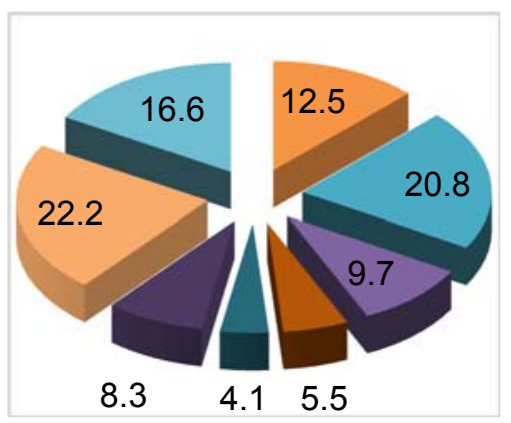

You can receive help from the teacher through additional questions - It is objective

- Sufficient thinking time

It is fairer

- It takes into account both knowledge and the ability to summarize

no room for interpretation

Figure no. 5: The students' replies concerning their reasons for preferring a certain method

Table no. 5: The students' replies concerning their reasons for preferring a certain method

Explain your choice for the previous item.

Answers

(\%)

\begin{tabular}{|l|c|}
\hline $\begin{array}{l}\text { It is a more precise measurement of the } \\
\text { level of knowledge }\end{array}$ & 22,2 \\
\hline It is objective & 20,8 \\
\hline $\begin{array}{l}\text { No answer } \\
\begin{array}{l}\text { Additional questions (help from the } \\
\text { teacher) }\end{array}\end{array}$ & 16,6 \\
\hline Sufficient thinking time & 12,5 \\
\hline There is no room for interpretation & 9,7 \\
\hline It is fairer & 8,3 \\
\hline
\end{tabular}

It takes into account both knowledge and the ability to summarize

Students consider that oral assessment is objective because it measures the level of knowledge more precisely $(22.2 \%)$, teachers are objective $(20 \%)$, students that are stuck can get helpful questions, there is more time to think, etc.

Analysis of students' answers denotes the fact that they are most often evaluated in the examination period through written evaluation methods, i.e. exams with essay subjects or multiple-choice tests. Students consider this method of assessment to be objective. However, we find that students want to be evaluated more often by way of oral examinations because they measure the level of knowledge and skills acquired in a more precise manner. Through oral assessment, students undertake a self-questioning, a cognitive self-evaluation and self-assessment of acquired competencies.

Taking into account the results obtained in this interview, correlated with the performance generally obtained by the students, we advocate rather for an ongoing evaluation, not just a final one, i.e. in the examination period. Students' grades obtained during the semester express the quality and the degree of improvement, since they are constantly adjusting their learning efforts, reducing the gap between the amount of knowledge taught and the amount of developed skills. Regardless of the evaluation method used in verifying students' knowledge, we consider it useful to place a special emphasis on the development of the student's thinking by asking for critical answers based on logic, trying to give a formative value to the moment of assessment (Iucu, 2001). We note that the periodical evaluation of the students, i.e. during the entire semester, at each class, ensures their active participation in courses and seminars and, thus, their complete involvement in the learning process. The frequency of the assessment contributes to the improvement of the intellectual activity style, it better outlines the activity of the students and, implicitly, of the teacher. The contribution of the assessment to improving the students' level of knowledge must be seen in various contexts, the assessment only fulfilling its purpose through the creative application of the principles of modern didactics and the achievement of unity between the students' capacity for intellectual activity and the effort made (Jucan, 2009).

In order to influence students in a positive way, in order to achieve a formative assessment, learning and teaching, we consider it necessary to use subjects that require the students to make a selection of the studied material, giving it new meaning and a new structure in the sense of grouping and essentializing the information and presenting it in a personal, original, even creative form. We note that, along with the elements and aspects based on memory and memorization, which are inevitably part of any test, an appropriate place must be reserved for subjects that require critical thinking and relevant intellectual activity. These are questions that require students to perform analyses, comparisons, and classifications, to reveal causal relationships, to provide substantial reasoning, to formulate 
explanations, to make generalizations, abstractions, etc. When grading, the evaluator will discern between the memorizing exercise and the involvement of thinking, appreciating and encouraging any progress made by the student. Special attention will be given to encouraging students towards operationalizing the content studied, applying it in different and varied contexts, practicing mental operations, manifesting originality and personal creativity.

In order for teachers to achieve an assessment of the students that is as objective as possible, we consider the following important: clear and rigorous clarification of the didactic objectives pursued through the evaluations; the level of the minimum admitted performance and the explanation of the criteria on which the appreciation of the actual performances of the students will be based; combining several assessment techniques (written, oral, practical tasks) in assessing the extent to which one and the same teaching objective has been achieved, which must be doubled by informing the students of the deficiencies recorded after each of these tests; the split-half method consisting of dividing the examination/ test in two equally relevant and difficult parts, each part being evaluated separately, with the separate assessments then combined and correlated; explaining and using grading scales, namely unitary grading scales based on the breakdown of the task to be solved in clear subtopics to be marked according to a prior agreement established between the teacher and the student.

\section{Conclusions}

We recommend the practice of a formative assessment of the students that would facilitate learning, providing each student with information about the evolution of their learning and the opportunity to monitor their own progress, to consciously build the progression of knowledge, and in which the adjustment of the activity is foremost aimed at the educational strategies employed by the teacher.

We also find that the objective didactic assessment of the students' performance needs to be continuous, systematic, flexible, and based on a variety of methods, techniques and assessment tasks.

\section{Authors note:}

Jucan Dana is Lecturer in the Department of Educational Sciences, Faculty of Psychology and Education Sciences, Babeş-Bolyai University, PhD in Education Sciences. Her research is in the field of university education, more precisely focused on teaching, learning, evaluation, didactic strategies, intellectual activity, taking notes.

\section{References}

Bocoş, M., Jucan, D. (2017). The theory and methodology of teaching. The theory and methodology of assessment. Pitești: Paralela 45 Publishing House.

Stan, C. (2001). Self-evaluation and didactic evaluation ClujNapoca: Cluj University Press.

Jucan, D. (2009). Students' intellectual activity strategies. ClujNapoca: House of the Scientific Book Publishing House.

Chiş, V. (2005). Contemporary pedagogy - competency pedagogy. Cluj-Napoca: House of the Scientific Book Publishing House.

Ionescu, M. (coord.). (2005). Current concerns in the education sciences, volume I. Cluj-Napoca: Eikon Publishing House.

Manolescu, M. (2006). Educational assessment. Methods, techniques, tools. Bucharest: Meteor Press Publishing House.

Păun, E., Potolea, D. (2002). Pedagogy. Theoretical basis and applicative approaches. Iaşi: Polirom Publishing House.

Iucu, R.B. (2001). Teaching in school. Theoretical and applicative perspectives. Iaşi: Polirom Publishing House. 